\title{
Influence of polymers on the stability of Gudao crude oil emulsions
}

\author{
Lin Meiqin ${ }^{1}$, Zhang Chunling ${ }^{1}$, Zong Hua ${ }^{2}$, Li Mingyuan${ }^{1}$, Fang Hongbo ${ }^{2}$ \\ and Guo Jixiang ${ }^{1}$ \\ ${ }^{1}$ Enhanced Oil Recovery Research Center, China University of Petroleum, Beijing 102249, China \\ ${ }^{2}$ Shengli Engineering Design and Consulting Company Ltd, Sinopec, Dongying, Shandong 257026, China
}

\begin{abstract}
The influence of different types and concentrations of polymers on the stability of Gudao crude oil emulsion was investigated by measuring the volume of water separated from the emulsions and the interfacial shear viscosity of the oil/water interfacial film. Experimental results indicate that the simulated water-in-oil emulsion with $40 \mathrm{mg} / \mathrm{L}$ of partially hydrolyzed polyacrylamide (HPAM) $3530 \mathrm{~S}$ could be easily broken by adding demulsifier $\mathrm{C}$ and was readily separated into two layers. However, HPAM AX-74H and hydrophobically associating water-soluble polymer (HAP) could stabilize the crude oil emulsion. With increasing concentration of AX-74H and HAP, crude oil emulsions became more stable. Water droplets were loosely packed in the water-in model oil emulsion containing HPAM 3530S, but water droplets were smaller and more closely packed in the emulsion containing AX-74H or HAP. The polymers could be adsorbed on the oil/water interface, thereby increasing the strength of the interfacial film and enhancing the emulsion stability.
\end{abstract}

Key words: Polymer, crude emulsion, stability

\section{Introduction}

Polymer flooding has been used in many oilfields in China since the 1980s (Shen, 2003; Delamaide and Wang, 1994). An additional $8-12 \%$ of original oil in place (OOIP) can be recovered by polymer flooding after water flooding. However, some problems arise during polymer flooding. One of the problems is the separation of water from crude oil because the polymer used in flooding can enhance the stability of crude oil emulsions (Deng et al, 2002a; Kang et al, 1997; $\mathrm{Li}$ et al, 1997). In order to solve this problem, demulsification of Gudao crude emulsion formed during polymer flooding was studied, and the influence of different types and concentrations of polymers on the stability of Gudao crude emulsions was investigated.

\section{Experimental}

\subsection{Materials}

The crude oil used was from the Gudao Oilfield, with acid number of $3.64 \mathrm{mg}(\mathrm{KOH}) / \mathrm{g}($ oil $)$. The demulsifier $\mathrm{C}$ was $\mathrm{PO} /$ $\mathrm{EO} / \mathrm{PO}$ triblock polyether, with mole ratio of $\mathrm{PO} / \mathrm{EO} / \mathrm{PO}$ of 1:1:2 (PO-propylene oxide, EO-epoxyethane). The demulsifier and crude oil were provided by the Shengli Engineering Design and Consulting Co. Ltd.

Hydrophobically associating polymer (HAP) was a Yanshan Chemical Plant product, with a viscosity-average molecular weight of $1.09 \times 10^{7}$ and degree of hydrolysis of $25 \%$. HAP is an anionic polymer and its molecular structure was reported in the literature (Jiang et al, 2003). The partially hydrolyzed polyacrylamide (HPAM) was a Pfizer product, named HPAM 3530S, having a viscosity-average molecular weight of $1.70 \times 10^{7}$ and degree of hydrolysis of $26 \%$. Polymer AX-74H was a Mitsui Chemicals Inc., Japan product, having a viscosity-average molecular weight of $1.99 \times 10^{7}$ and degree of hydrolysis of $25 \%$.

Other chemicals used in the experiments, such as $\mathrm{NaCl}$, $\mathrm{NaHCO}_{3}, \mathrm{MgSO}_{4}, \mathrm{CaCl}_{2}$ and $\mathrm{KCl}$ were commercially available, analytical reagents. The simulated formation water used had a salinity of $5,705 \mathrm{mg} / \mathrm{L}$, and its major ion composition is listed in Table 1.

Table 1 Major ion composition of simulated formation water

\begin{tabular}{ccccccc}
\hline Ion & $\mathrm{Cl}^{-}$ & $\mathrm{HCO}_{3}^{-}$ & $\mathrm{SO}_{4}^{2-}$ & $\mathrm{Na}^{+}+\mathrm{K}^{+}$ & $\mathrm{Mg}^{2+}$ & $\mathrm{Ca}^{2+}$ \\
\hline Concentration, $\mathrm{mg} / \mathrm{L}$ & 3068.3 & 400.2 & 89.9 & 2038.1 & 28.3 & 80.2 \\
\hline
\end{tabular}

\footnotetext{
* Corresponding author. email: linmq@cup.edu.cn

Received January 8, 2007
} 


\subsection{Experimental methods}

\subsubsection{Measurement of emulsion stability}

The polymer solution was prepared by dissolving the polymer in simulated formation water.

The water-in-oil (W/O) emulsion was prepared by adding $8 \mathrm{ml}$ of polymer solution to $12 \mathrm{ml}$ crude oil. The volume ratio of crude oil to water was 60:40. After standing for 20 minutes at room temperature, the mixture was sheared with a stirrer for 160 seconds to obtain polymer-containing W/O emulsion, in which the concentration of polymer was in the range of $0-120 \mathrm{mg} / \mathrm{l}$.

Demulsification of $\mathrm{W} / \mathrm{O}$ emulsion was carried out by adding $0.1 \mathrm{ml}$ of $60 \mathrm{mg} / \mathrm{l}$ demulsifier $\mathrm{C}$ into $20 \mathrm{ml}$ the emulsion. After being mixed evenly, the emulsion was transferred to a graduated cylinder with a stopper and then was put in a water bath at $50{ }^{\circ} \mathrm{C}$ for demulsification.

The volume of water separated from the emulsion was measured with time and the separation rate of water, $V_{t} / V_{0} \times$ 100 , was calculated. $V_{t}$ is the volume of water separated from $\mathrm{W} / \mathrm{O}$ emulsion at time $t$ and $V_{0}$ is the total volume of water used for preparing the $\mathrm{W} / \mathrm{O}$ emulsions. The emulsion stability was evaluated by measuring the value of water separation rate.

\subsubsection{Microscope observation}

The microstructures of the $\mathrm{W} / \mathrm{O}$ emulsions made up of $60 \%$ by volume of model oil (a mixture of $10 \%$ by weight Gudao crude oil and $90 \%$ by weight jet fuel) and $40 \%$ by volume of polymer solution were observed with XS-18 microscope (Jiangnan Optoelectronics Co. Ltd.). In the waterin-model oil emulsion, the concentration of polymer was 40 $\mathrm{mg} / \mathrm{L}$.

\subsubsection{Measurement of interfacial shear viscosity}

The interfacial shear viscosity of water-in-model oil emulsion was measured with a SVR·S interfacial viscoelasticity meter (Kyowa Kagaku Co., Japan) at $30{ }^{\circ} \mathrm{C}$.

\section{Results and discussion}

\subsection{Influence of polymers on W/O emulsion stability}

Fig. 1 is a plot of volume percent water separated as a function of time for one control emulsion without any polymers and three emulsions containing different polymers of HPAM $3530 \mathrm{~S}, \mathrm{AX}-74 \mathrm{H}$ and HAP, respectively. The concentration of polymer in the emulsions was $40 \mathrm{mg} / \mathrm{L}$. Fig. 1 shows that there existed significant difference in the stability of $\mathrm{W} / \mathrm{O}$ emulsions containing different polymers. Polymers AX-74H and HAP could improve the stability of W/O emulsions, with only a small amount of water separated from the emulsions, However, HPAM 3530S could reduce the stability of emulsion, and a large amount of water was separated from the emulsion.

Droplet size distribution was observed under microscope for the prepared water-in-model oil emulsions, as shown in Fig. 2. The water-in-model oil emulsion containing HPAM 3530 S, was an unstable emulsion, in which water droplets were unevenly dispersed in the oil phase, and the model oil was present as large oil drops without containing any water.

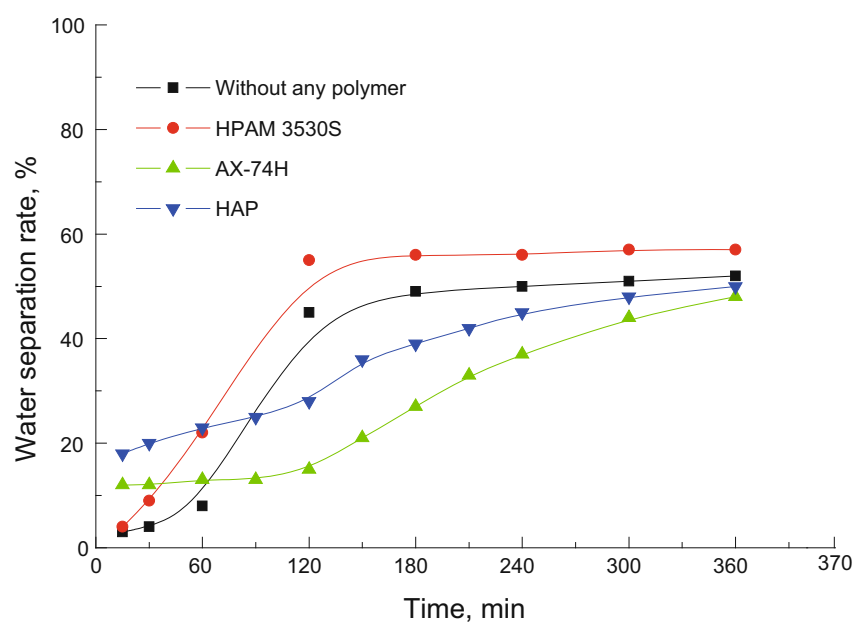

Fig. 1 Influence of different polymers on emulsion stability

However, the water droplets formed a closely packed layer on the microscope slide if the water-in-oil emulsion contained AX-74H and HAP respectively and water droplets were smaller, compared with the emulsion without any polymer. This phenomenon indicates that the emulsions containing AX-74H or HAP were more stable. However, the water droplets were unevenly dispersed in the emulsions containing HPAM 3530S, indicating lower stability of the emulsion than the emulsion without any polymer.

The molecular weights of these three polymers used in the experiments were different. HAP had the smallest molecular weight (Ren et al, 2006). The molecular weight of AX-74H was significantly higher than those of other polymers. The solution of polymer of higher molecular weight would have higher viscosity, therefore the friction between water droplets and model oil in the emulsion containing such a polymer would increase and consequently the sedimentation resistance to water droplets would rise (Deng et al, 2002b). As a result, the amount of water separated from emulsion containing AX$74 \mathrm{H}$ decreased.

Interfacial tension of the emulsion system containing HAP was lower than that of the system containing HPAM 3530S, because of the existence of a small amount of surfactant in HAP (Taylor and Nasr-El-Dinb, 1998). The interfacial energy would decrease with decreasing interfacial tension. This was advantageous to reducing thermodynamic instability and the formation of more well-dispersed water droplets in oil. The stability of emulsion, in turn was increased and demulsification became more difficult.

\subsection{Influence of polymer concentration}

$\mathrm{W} / \mathrm{O}$ emulsions with different polymer concentrations were prepared with the same volume ratio of crude oil to water. Fig. 3 illustrates that the amount of water separated from emulsions containing $\mathrm{AX}-74 \mathrm{H}$ or HAP decreased as the concentration of polymer in the emulsion increased, the separation rate of water changed quickly when the concentration of polymer in the emulsion was lower than 20 $\mathrm{mg} / \mathrm{L}$. This indicates that the polymer concentration could influence the emulsion stability significantly. The separation 


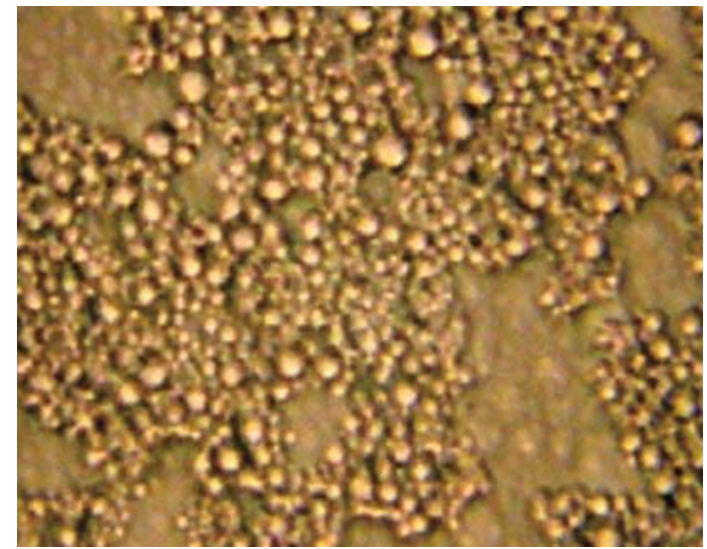

(a) Emulsion without any polymer

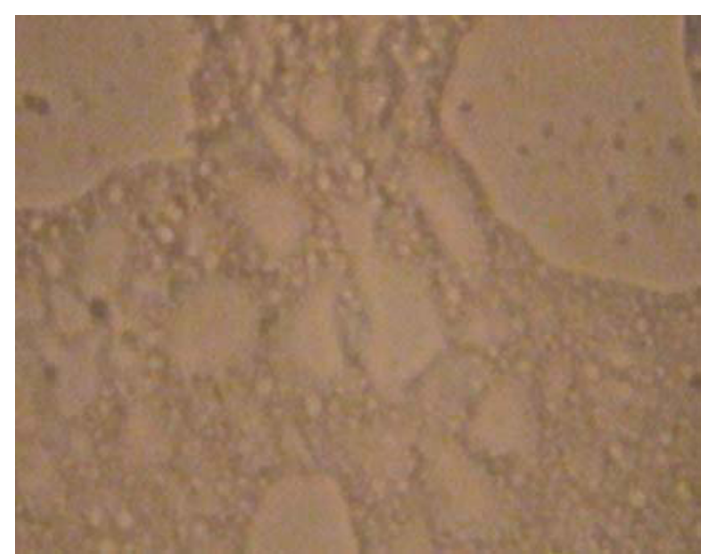

(b) Emulsion containing HPAM 3530 S

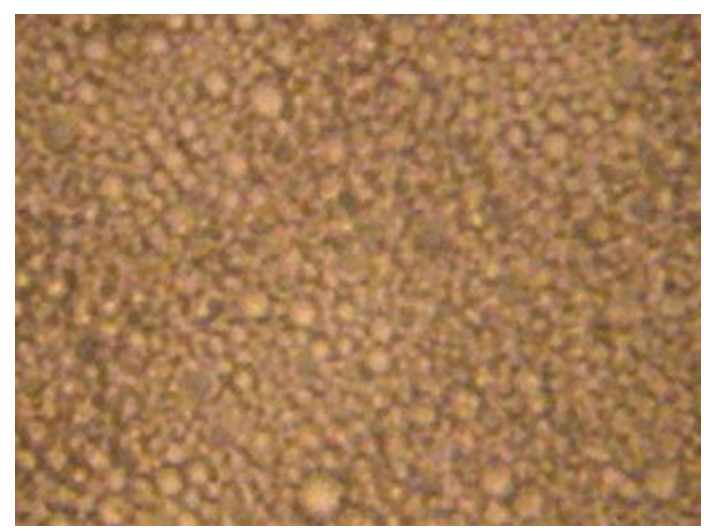

(c) Emulsion containing $\mathrm{AX}-74 \mathrm{H}$

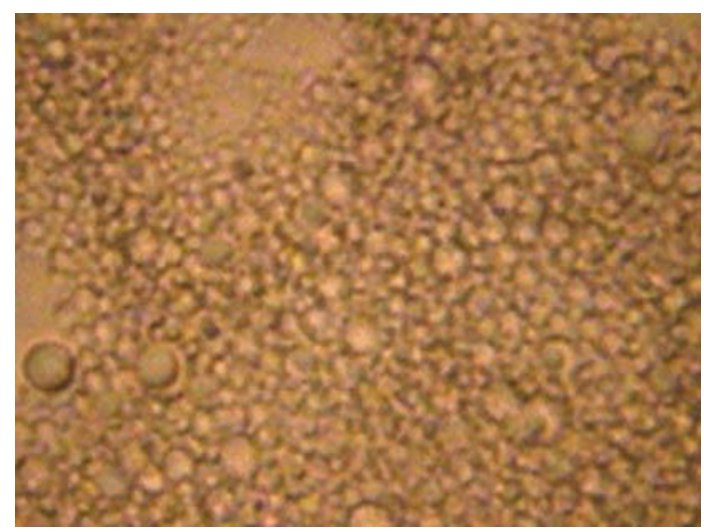

(d) Emulsion containing HAP

Fig. 2 Photograph of emulsions with or without polymers rate of water from the emulsion containing HPAM 3530 S decreased when the polymer concentration in the emulsion was lower than $20 \mathrm{mg} / \mathrm{L}$ and increased when the polymer concentration in the emulsion was higher than $20 \mathrm{mg} / \mathrm{L}$. Approximately $55 \%$ by volume of water could be separated from the emulsion when the concentration of HPAM $3530 \mathrm{~S}$ in the emulsion was higher than $40 \mathrm{mg} / \mathrm{L}$.

The emulsion containing AX-74H or HAP was more stable than the emulsion containing HPAM 3530 S when the polymer concentration in the emulsion was higher than 40 $\mathrm{mg} / \mathrm{L}$.

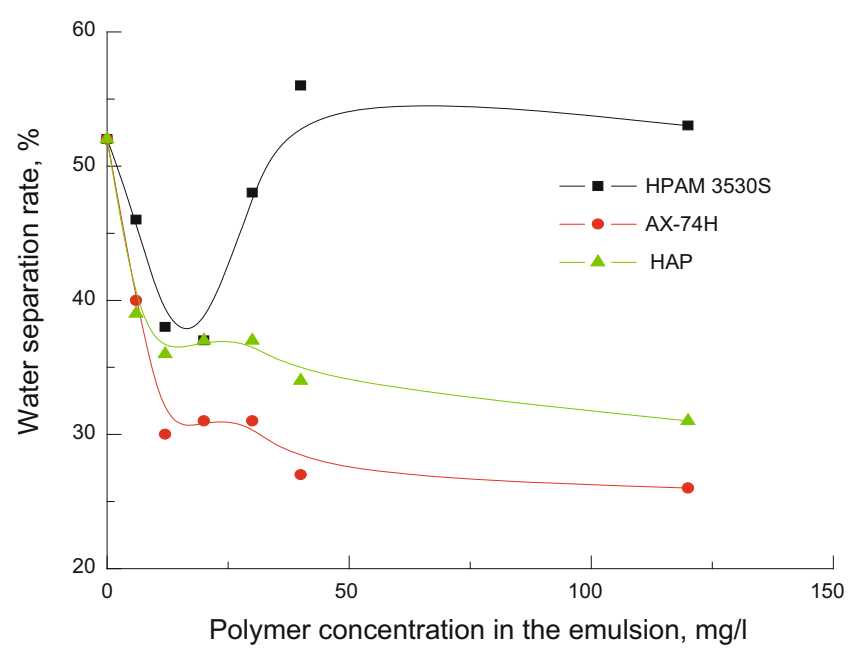

Fig. 3 Influence of polymer concentration on emulsion stability

\subsection{Influence of polymer on interfacial shear viscosity}

The stability of W/O emulsion is dominated by the strength of oil/water interfacial film, and the strength of interfacial film can be characterized by the interfacial shear viscosity. The higher the interfacial shear viscosity, the stronger the film, and the more stable the emulsion ( $\mathrm{Li}$ et al, 2002a, 2006). Fig. 4 shows the interfacial shear viscosity of the film between model oil and water in the presence of polymers (HPAM 3530S, AX-74H, and HAP). The interfacial shear viscosity of the film between model oil and water rose sharply with AX-74h concentration, and was significantly higher than that of the film between model oil and water in the presence of HPAM 3530 S. In this study, polymers AX$74 \mathrm{H}$ and HPAM $3530 \mathrm{~S}$ were both partially hydrolyzed polyacrylamide, but AX-74H had a higher relative molecular weight than $3530 \mathrm{~S}$. When polymers were adsorbed on the interface between model oil and water, the polymer and the interfacial active components, such as asphaltene, resin fractions in crude oil would form a strong interfacial film (Li et al, 2007; Cao et al, 2004). This film prevented the coalescence of water droplets, therefore the emulsion was stable (Li et al, 2002b; Dicharry et al, 2006). Polymer AX$74 \mathrm{H}$ had a higher molecular weight than HPAM 3530S, the emulsion containing AX-74H was more stable than the emulsion containing HPAM 3530S under the experimental 
conditions (Figs.1 and 3). This phenomenon might be caused by the synergistic effect of polymer and demulsifier $\mathrm{C}$.

Fig. 4 also shows that the interfacial shear viscosity of the interfacial film between model oil and water increased with increasing HAP concentration, and Fig. 3 shows that the water separation rates of emulsions containing HAP and AX-74 decreased with increasing polymer concentrations. HAP had a different molecular structure from HPAM, but it had the same effect on the interfacial shear viscosity and the stability of the emulsions.

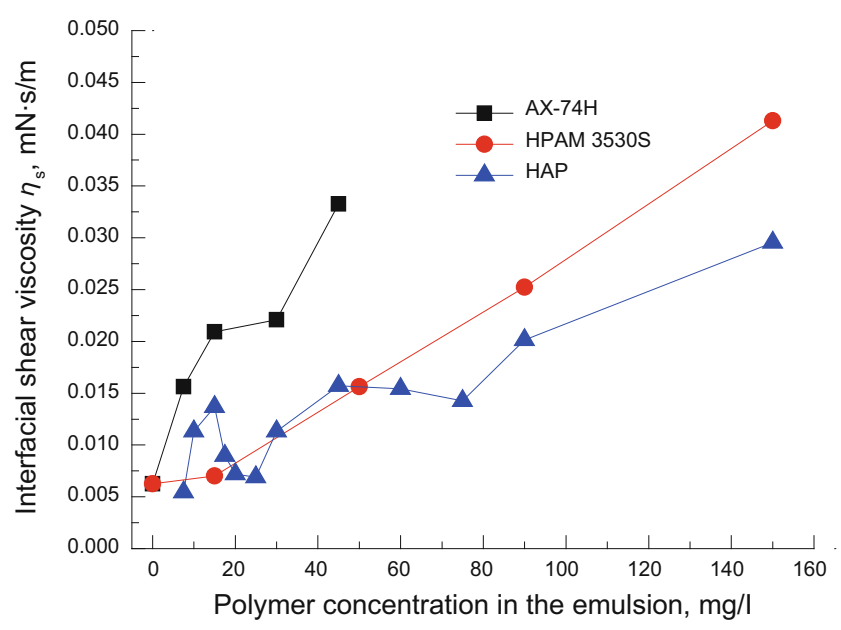

Fig. 4 Influence of polymer concentration on interfacial shear viscosity of the film between model oil and water

\section{Conclusions}

1) Demulsifier $\mathrm{C}$ could easily break $\mathrm{W} / \mathrm{O}$ emulsion with $40 \mathrm{mg} / \mathrm{L}$ of HPAM $3530 \mathrm{~S}$, but the rate of demulsification and the water separation rate decreased for W/O emulsions with $40 \mathrm{mg} / \mathrm{l}$ of polymer AX-74H or HAP.

2) After adding $0.1 \mathrm{ml}$ of $60 \mathrm{mg} / \mathrm{L}$ demulsifier, the rate of separation of water from the emulsion initially decreased, then increased with the increase in HPAM 3530S concentration in the emulsion, and finally leveled off with increasing $3530 \mathrm{~S}$ concentration. The emulsion was the most stable, with the least amount of water separated, when the HPAM 3530 S concentration in the emulsion was in the range of 12 to $20 \mathrm{mg} / \mathrm{L}$.

3) The rate of demulsification and the water separated from the emulsion decreased significantly with increasing concentration of AX-74H or HAP when $0.1 \mathrm{ml}$ of $60 \mathrm{mg} / \mathrm{L}$ demulsifier was added into the emulsion.

\section{Acknowledgements}

This paper was supported by National Basic Research Program of China (Grant No. 2005CB221305)

\section{References}

Cao X L, Li Y, Jiang S X, et al. A study of dilational rheological properties of polymers at interfaces. Journal of Colloid and Interface Science. 2004. 270(2): 295-298

Delamaide E and Wang D M. Daqing oil field, the success of two pilot initiates first extension of polymer injection in a giant field. SPE/ DOE Improved Oil Recovery Symposium held in Tulsa, Oklahoma, 17-20 April 1994 (SPE paper 27819)

Deng S B, Bai R B, Chen J P, et al. Effects of alkaline/surfactant/polymer on stability of oil droplets in produced water from ASP flooding. Colloids and Surfaces A: Physicochemical and Engineering. Aspects. 2002a. 211(2-3): 275-284

Deng S B, Zhou W S, Chen Z X, et al. Effects of polyacrylamide on settling and separation of oil droplets in polymer flooding produced water. Environmental Science. 2002b. 23(2): 69-72 (in Chinese)

Dicharry C, Arla D, Sinquin A, et al. Stability of water/crude oil emulsions based on interfacial dilatational rheology. Journal of Colloid and Interface Science. 2006. 297(2): 785-791

Ji ang G Y, Ren K, Xu C M, et al. Synthesis technology and property evaluation of hydrophobically association polymer solution. Journal of the University of Petroleum. 2003. 27(6): 80-82 (in Chinese)

Kang W L, Yue X A and Hu J B. The stability of polymer effect on emulsion and liquid membrane. Acta Petrolei Sinica. 1997. 18(4): 122-125 (in Chinese)

Li D P, Fan Q X and Zhou D. Laboratory study on coagulation test for treating the synthetic sample of oilfield HPAM waste water. Environmental Chemistry. 1997. 16(6): 560-565 (in Chinese)

Li M Y, Guo J X, Lin M Q, et al. Studies on properties of interfacial active fractions from crude and their effect on stability of crude emulsions. Journal of Dispersion Science and Technology. 2006. 27: 677-687

Li M Y, Xu M J, Lin M Q, et al. The effect of HPAM on crude oil/water interfacial properties and the stability of crude oil emulsions. Journal of Dispersion Science and Technology. 2007. 28(1): 189-192

Li M Y, Xu M J, Ma Y, et al. Interfacial film properties of asphaltenes and resins. Fuel. 2002a. 81(14): 1847-1853

Li M Y, Xu M J, Ma Y, et al. The effect of molecular parameters on the stability of water-in-crude oil emulsions studied by IR and UV spectroscopy. Colloids and Surfaces, A: Physicochemical and Engineering Aspects. 2002b. 197(1-3): 193-201

Ren K, Wang J L, Lin M Q, et al. Rheological properties of hydrophobically associating polyacrylamide solution. Petroleum Science. 2006. 3(2): 66-72

Shen P P. New achievements in fundamental research of enhanced oil recovery greatly. China Basic Science. 2003. (2): 9-14 (in Chinese)

Taylor K C and Nasr-El-Dinb H A. Water-soluble hydrophobically associating polymers for improved oil recovery: A literature review. Journal of Petroleum Scienece and Engineering. 1998. 19(3-4): 265-280

(Edited by Sun Yanhua) 